\title{
CONTROL OF SCALE INSECT PESTS OF OLIVES IN THE SACRAMENTO AND SAN JOAQUIN VALLEYS
}

\author{
E. M. STAFFORD ${ }^{1}$
}

This leaflet has been prepared in response to numerous requests from olive growers for help in combating the black, the oleander, and the olive parlatoria scales of olives. Other scales are occasionally found on olives, notably the greedy scale, but in general they yield to the same methods of control as the three species discussed herein.

\section{Black Scale Injury}

The black scale, Saissetia oleae, is the most destructive insect pest of olives in California. Although hot, dry weather kills large numbers of the young, this pest is becoming more and more serious. In summer the eggs hatch and the yellowcolored insects crawl from the twigs to the leaves, where they settle and feed. Soon they begin to excrete a sticky liquid, or honeydew, which supports the growth of a black fungus. Often their feeding so weakens the trees that many leaves drop and the next season's crop is reduced. The sticky liquid and the black fungus cause much difficulty in the harvesting, handling, and processing of the fruit.

As the insects grow larger, the ridges on their backs are seen to form a characteristic "H" shape. In autumn the scales migrate to the small twigs. In late spring and early summer they grow rapidly, turn dark, shining brown to almost black, harden, and begin to lay great quantities of eggs which remain beneath the large, nearly hemispherical, hollow bodies. Many other fruit trees and ornamental plants are hosts of the black scale.

\section{Control of Black Scale}

Black scale may be controlled by tent fumigation, using hydrogen cyanide (HCN) gas from about mid-July through the autumn and winter until about March 1, after which the treatment might injure the developing fruit buds. Since this gas kills so rapidly, this treatment should be applied only by experienced and licensed operators. A dosage of $12 \mathrm{cc}$ of liquid HCN per unit of tree size is used for summer and autumn treatments. This should be increased during the late fall and winter, when the black scales are more advanced in development, or at any time when the trees are

\footnotetext{
${ }^{1}$ Assistant Entomologist in the Experiment
}

infested with other pests that require heavier dosages. In winter, trees may be fumigated during the daylight hours, provided the temperature is below $60^{\circ} \mathrm{F}$. Mission olive is more susceptible to cyanide injury than most other varieties and should be treated only at night, with a dosage not exceeding $16 \mathrm{cc}$ of liquid HCN per unit of tree size. In bright, warm weather all tents should be removed from the funigated trees 3 to 4 hours before sunrise, since with later night applications the gas may not be entirely dissipated by daybreak, and in conjunction with sunlight may cause injury to the twig tips and a browning of the fruit stems. In cloudy or cool weather, tents should be removed about 2 hours before sunrise.

Black scale may also be controlled by means of hydrogen cyanide liberated from a calcium cyanide dust applied in the orchard without the use of tents. ${ }^{2}$ From 40 to 50 pounds of this dust per acre must be applied with a power duster in July or early August. Good control depends upon enveloping the trees in a cloud of dust in the shortest possible time. The orchard soil should be worked smooth so that the machine may operate at high speed. The duster, with the discharge directed upwards at an angle is driven in every second or third tree-row middle so that large rectangular areas of the orchard are covered quickly. This work should be undertaken only by experienced'and licensed operators wearing gas masks for protection against hydrogen cyanide. The application should be started at the side of the orchard to which the dust might be expected to drift, in order that the operator may work in a gas-free atmosphere. For satisfactory results the dust must be applied in a nearly complete calm. Where oleander or olive parlatoria scales are also present one may obtain some control of these insects by increasing the application to between 60 and 80 pounds per acre.

Since hydrogen cyanide is a deadly poison to human beings, livestock, pets, and poultry, special precautions must be taken whenever calcium cyanide dust is discharged into the air. All persons and animals must be removed to a

\footnotetext{
2 This method of control is based upon studies reported in: Kirkpatrick, A. F. The control of black scale in olive orchards by calcium cyanide dusting. Jour. Econ. Ent. 34(6):722-77.
} 
safe distance from the orchard before dusting is started and until the gas is dissipated after the treatment--usually within an hour. Besides the operator, another experienced man wearing a gas mask designed for protection against hydrogen cyanide should be present to prevent anyore from approaching too close to the dusted orchard and to warn of any unexpected drifts. There has been no complete study of the exact distance required for safety. The precautions necessary are influenced by atmospheric conditions and by topography. The practice has been to remove all persons and animals to at least 200 yards from the orchard before treatment is started. Many orchards are so close to towns or busy highways, however, as to make it impossible to use this "open dusting" method at all.

Black scale may be controlled by oil sprays applied in the summer after nearly all the eggs have hatched. In the southern San Joaquin Valley this time usually occurs late in July or early in August. As a rule, oil sprays should be applied before mid-August. A summer oil ${ }^{3}$ of light-medium grade is recommended, used at the rate of $1-2 / 3$ to 2 gallons per 100 gallons of water.

The amount of control resulting depends almost entirely on how well the spraying is done. Thorough spray coverage of trunk, limbs, and leaves is essential. Most small trees will require 10 gallons, while large trees may require 40 to 60 . The most successful operator works systematically. One system has been to spray the inside limbs and skirts of the tree directing the spray from a position close to the trunk; then he moves out and sprays the outside, circling the tree until he arrives opposite the place where the spraying was started. Next, the operator again moves inside and sprays the limbs and skirts from this new angle. Moving out, he then continues to spray the tree from the outside until he has completely circled it. The use of spray towers facilitates treatment of high treetops.

In the Sacramento and northern San Joaquin valleys the hatch of black scale eggs sometimes becomes extended through the summer and fall. This delay in hatching is more pronounced in cool summers. In such areas a medium-grade summer oil (heavier than the light-medium) should be used in August. Application is at the rate of $1-2 / 3$ to 2 gallons per 100 gallons of water. The use of oil sprays in fall or early winter should be avoided because of possible injury to the trees. Orchards that have not been irrigated for some time are more susceptible to such damage. When the temperature is above $90^{\circ} \mathrm{F}$ spraying should be avoided.

In winter the scales are larger and more dif-

The California State Department of Agriculture classification is used for all oils mentioned. These are all petroleum spray oils for foliage and should be of $92 \mathrm{U} . \mathrm{R}$. or higher. ficult to kill. Some growers, however, have obtained control by spraying in January or in the first half of February. A medium-grade summer oil, used at the rate of 3 gallons per 100 gallons of water, is recommended. Where pruning is contemplated or is a general practice, it should be done before spraying to aid in obtaining a thorough spray coverage.

\section{Oleander Scale Injury}

The oleander scale, Aspidiotus hederae, is armored and has a yellow body beneath a whitish covering. The covering of the female is small and circular; that of the male more elongate and still smaller. Apparently the natural enemies sometimes increase sufficiently to give commercial control. In some places in the Sacramento and San Joaquin valleys this pest has again become serious after having been very scarce for several years. It often appears in greatest numbers on the leaves of the lower inside part of the tree.

Most of the overwintering scales are adult females that have not begun to produce young. The first summer brood starts to develop in April; and a second brood, which overwinters, is hatched in late July and August.

The oleander scale seldom if ever becomes numerous enough to weaken the tree noticeably. When, however, it settles upon a fruit, that part of the olive immediately beneath and surrounding the scale is delayed in maturing; as a result, this area remains green, whereas the rest of the olive attains the natural dark color. When scale settles on olives early in the season, many fruits become pitted and deformed; these must be culled out, because even lightly infested olives do not make good pickles. Heavy infestations may reduce the oil content as much as 25 per cent.

\section{Olive Parlatoria Scale Injury}

The female olive parlatoria scale, Parlatoria oleae, has a small gray covering with a small black spot to one side of the center; the outline is less circular than that of the oleander scale. The males are elongated in comparison with the females. In both sexes, the body beneath the shell is purple. Where found upon twigs, the scales frequently cause a purple discoloration and slight deformity of the wood. Great numbers may occur on trees; often the scales overlap. Frequently the fruit is infested and sometimes small branches are killed. Nevertheless, heavily infested trees may show no apparent decrease in yield. At present the olive parlatoria scale is widespread in Fresno County and is spreading rapidly in Tulare and Madera counties. Isolated infestations have been found in California at rather great distances from these counties, but have usually been traced to the transportation of plants from the infested areas. The scale is likely to spread farther, since it thrives in the 
climate of the Sacramento and San Joaquin valleys, has few natural enemies, and can live on over 180 different species of plants.

There are two broods each year. Adult females overwinter and lay eggs in late March. The eggs hatch in early May, and a second brood starts hatching in late July.

Infested olives do not make good pickles. Dark purple spots appear on the immature fruit (fig. 1). These appear more pronounced as the olive nears maturity and turns straw colored. Heavy infestations may reduce the oil content as much as 20 per cent.

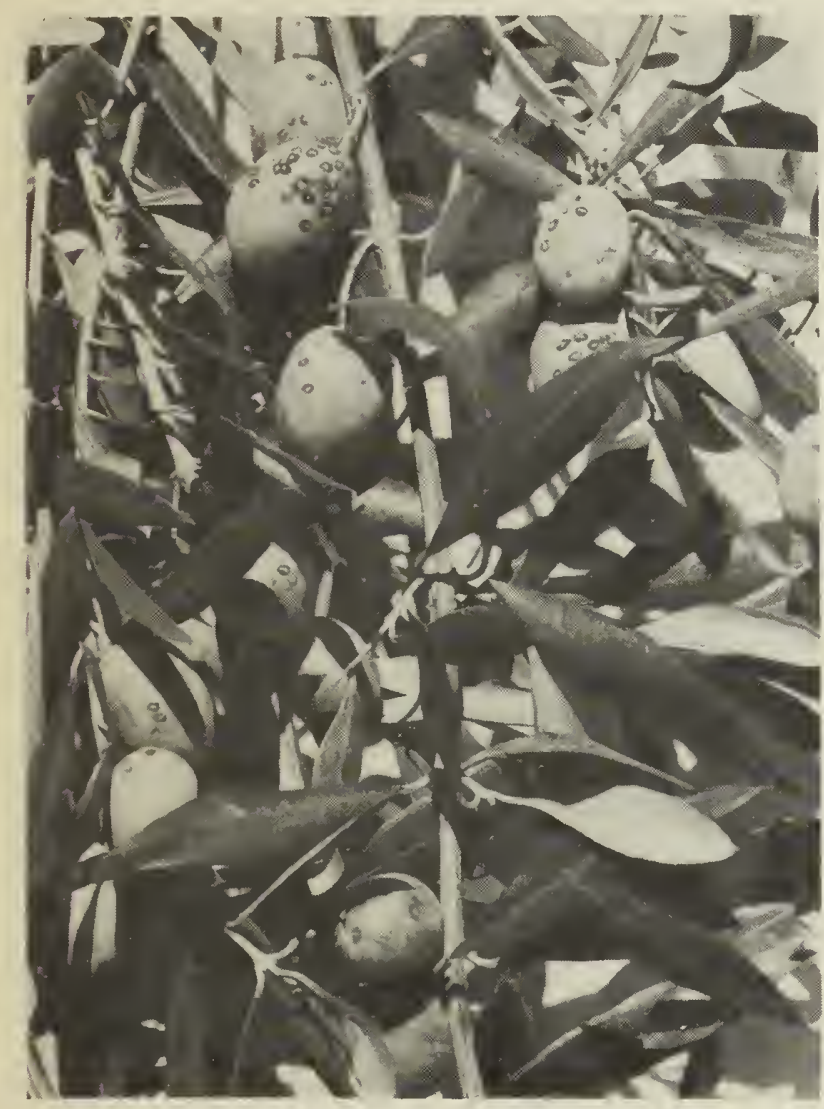

Fig. 1.--The olive scale, Parlatoria oleae (Colvée), on ripening fruits.

Control of Oleander and Olive Parlatoria Scales

Oleander and olive parlatoria scales may be controlled by tent fumigation as outlined under "Control of Black Scale." When fumigating for either of these pests, one must use heavier dosages of HCN than are required for black scale. Until the olives are harvested, the dosage should not be more than $20 \mathrm{cc}$ per unit of tree size.
After harvest the amount may be increased to 22 cc per unit. As tree conditions may vary with the seasons, it may be well to test for tree injury before using an increased schedule. In the fumigation of Mission olive, the dosage should not exceed $18 \mathrm{cc}$ of liquid $\mathrm{HCN}$ per unit of tree size. All tents should be removed from the fumigated Mission trees 3 or 4 hours before sunrise in bright, warm weather; well before sunrise if the weather is cloudy or cool.

Oil sprays for controlling these scales may be applied either in winter or in summer. In the winter a medium-grade summer oil (heavier than light-medium) at 3 gallons of actual oil per 100 gallons of water should be applied in January, or February, or in the first week of March. The later in March the oil sprays are applied, the greater the danger of injuring the fruit buds, with consequent reduction in crop. In summer a spray of 2 gallons of medium-grade summer oil per 100 gallons of water should be applied from mid-June to mid-July. Since oleander and olive parlatoria scales are more difficult to kill than young black scales in the summer, thoroughness of application is imperative. The control has generally been more successful on small trees, where good spray coverage is much less difficult to achieve. Where black scale is also a problem, the application may be delayed until about the first of August.

Where infestations of olive parlatoria scale have become very heavy, control will probably not be attained in one application; a winter spray followed by a summer spray very likely will be needed. The two sprays should be applied the same year; there is evidence that the olive scale increases rapidly after an attempted control that has been only partially effective.

\section{Oil-Spray Injury}

Oil-spray injury has sometimes been noted, especially in the southern San Joaquin Valley. Not all the causes are known. Injury seems, however, most likely to result from spraying trees in reed of water, from treatment in very hot weather, and from heavy winds following the applications. Oil sprays in summer necessarily wet the fruit as well as the leaves and twigs. When such olives are pickled by the "green ripe" process, their pores become darker and more prominent than those of unsprayed olives. In the Spanish green process, an oil mottling appears on sprayed fruit. This mottling almost entirely disappears by the time the process is completed. Oil-sprayed olives have made dark ripe pickles of entirely satisfactory appearance. 
Digitized by the Internet Archive in 2012 with funding from University of California, Davis Libraries 